\title{
Cena
}

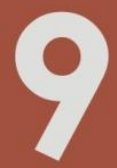

Dossiê Dança em Desdobramentos

PERIÓDICO DO PROGRAMA DE PÓS-GRADUAÇÃO EM ARTES CÊNICAS INSTITUTO DE ARTES | DEPARTAMENTO DE ARTE DRAMÁTICA UNIVERSIDADE FEDERAL DO RIO GRANDE DO SUL

\section{CONSIDERAÇÕES ACERCA DO FAZER TEATRAL CONTEMPORÂNEO}

Aline Sanfelici

Professora Adjunta I na Universidade Federal do Pará. Doutorado em Letras (Inglês) e Literatura Correspondente na UFSC (2011). Doutorado sanduíche na University of British Columbia, Vancouver, Canadá (2010). 


\begin{abstract}
RESUMO: Esse artigo discute duas questões relacionadas ao fazer teatral contemporâneo, a saber, a criação coletiva de peças e espetáculos e o problema da apropriação do texto para o palco. No que se refere ao primeiro ponto, discuto o sentido clássico do termo "dramaturgia" para apontar as razões do surgimento de trabalhos assinados coletivamente, observando também como se dá esse processo, suas dificuldades, e que papeis os membros do grupo teatral assumem no mesmo. No que se refere ao problema da apropriação, inicialmente diferencio esta de mera adaptação, e na sequência discuto questões acerca do diálogo entre culturas fonte e alvo, procedimentos eficazes a serem empregados, e como se dá a análise do produto resultante da apropriação. Em minhas considerações finais estabeleço relações entre as duas questões discutidas e suas motivações e capacidade transformadora.
\end{abstract}

PALAVRAS-CHAVE: Criação coletiva; apropriação; engajamento estético e ideológico.

ABSTRACT: This essay discusses two issues related to the contemporary theatrical activity, namely, collective creation of playtexts and of performances, and the issue of appropriation from the text to the stage. In what concerns the first matter, I discuss the classical meaning of the term "dramaturgy" so as to indicate the reasons for the emergence of works devised collectively, observing also how this process develops, what its difficulties are, and what roles the members of the theater company take on. In what concerns the issue of appropriation, initially I differentiate this one from mere adaptation, and in the sequence I discuss matters related to the dialogue between source and target cultures, effective procedures to be used, and how to analyze the resulting product of the appropriation process. In my final remarks I establish relations between the two issues discussed and their motivations and transformational power.

KEYWORDS: Collective creation; appropriation; aesthetic and ideological engagement.

\title{
INTRODUÇÃO
}

O consagrado teórico de performances Richard Schechner reconhece o poder inerente à atividade teatral de realizar transformações no mundo real, uma vez que o teatro é usado como uma forma de experimentar, agir e confirmar mudanças (SCHECHNER, 1988). De acordo com Schechner, o teatro pode lidar com as interações humanas mais problemáticas ou cercadas por tabus e, dentro dessa perspectiva, o meio teatral é entendido como muito mais do que fonte para comentários estéticos (e estáticos) sobre o que é visto no palco. Com efeito, o teatro torna-se uma chance de significar através da arte, ou seja, uma oportunidade de desenvolver reflexão e expressão sérias e 
críticas nos âmbitos políticos, sociais e culturais que permeiam uma dada produção teatral.

À luz dessa perspectiva, o presente artigo discute em nível teórico duas questões diferentes porém igualmente em voga em fazeres teatrais contemporâneos. Como veremos, os dois pontos aqui tratados estão indiscutivelmente ligados aos engajamentos e agendas dos artistas que os realizam e, portanto, apesar de suas naturezas distintas, estes pontos são capazes de encontrar motivações e propósitos em comum entre si, na prática teatral de hoje. O primeiro ponto é a criação coletiva de peças e espetáculos, realizada na maioria das vezes com o propósito de desenvolver a muitas mãos o texto e a encenação que tratam especificamente sobre o que o grupo está interessado em comunicar, a partir de seus anseios, interesses e contextos. Nessa discussão, analiso primeiramente o sentido clássico do termo "dramaturgia," e posteriormente aponto as razões do surgimento de trabalhos assinados coletivamente. Observo, também, como se dá esse processo de trabalho colaborativo, quais são suas dificuldades, e que papeis os membros do grupo teatral assumem e reivindicam.

O segundo ponto refere-se ao problema da apropriação de um texto base para o palco, em outra mídia e em outro contexto de recepção. Inicialmente ofereço uma diferenciação entre apropriação e mera adaptação, e na sequência discuto questões acerca do diálogo entre culturas fonte e alvo, procedimentos eficazes a serem empregados no processo de apropriação, e como se dá a análise do produto resultante da apropriação. $\mathrm{O}$ artigo encerra com considerações acerca dos pontos discutidos, nas quais estabeleço pontos em comum entre os processos de criação coletiva e apropriação, apontando para suas implicações para a cena e atividade teatral contemporâneas.

\section{DRAMATURGIA E CRIAÇÃO COLETIVA}

O sentido clássico do termo "dramaturgia" é ser a arte da composição de peças de teatro. Essa noção original destacava o trabalho centralizado na pessoa do autor. O autor (dramaturgo) buscava princípios e regras para a estrutura narrativa da sua construção dramática, isto é, da sua peça teatral. 
Essa noção básica de dramaturgia se expandiu após as inovações de Bertold Brecht, em sua teorização sobre o teatro épico. A partir de então, dramaturgia passa a considerar o texto de origem (a peça) e também sua encenação e recursos cênicos. Assim, a dramaturgia começa a ser vista como a prática totalizante do texto encenado, que tem por objetivo produzir um determinado efeito no espectador (PAVIS, 1998). Mary Luckhurst (2006) explica que, influenciado por Erwin Piscator, Brecht concebeu dramaturgia como algo que ocorre no palco, na instigação dos experimentos práticos de uma performance em preparação, e que engloba também a discussão acerca das funções do teatro (desenvolvendo assim as bases de seu teatro político). Em outras palavras, Brecht transforma a dramaturgia de mera escrita do texto para um processo de reflexão e experimentação no palco em si, criando, como coloca Luckhurst, uma nova forma de crítica interativa da performance, a medida que a mesma é construída dramaticamente.

A partir dos pressupostos de Brecht o entendimento do que constitui um dramaturgista (dramaturg) também evoluiu. Se no sentido tradicional o dramaturgo é o autor de dramas, atualmente, o dramaturgista é concebido como uma espécie de conselheiro literário e teatral (PAVIS, 1998), afiliado a uma certa companhia teatral ou a um encenador envolvido com a montagem de um dado espetáculo. O dramaturgista, hoje, prepara ou colabora na interpretação e realização cênica das peças (podendo ser, ainda, também aquele que escreve a peça). De acordo com o exposto por Pavis (1998), a partir de Brecht temos que o dramaturgista hoje também se responsabiliza por pesquisar documentação acerca da obra, adaptar ou modificar (e às vezes traduzir) o texto original, sozinho ou em parceria com o encenador, e atuar como uma espécie de crítico interno do espetáculo em elaboração, desde o processo de concepção, ensaios e produção. O dramaturgista contemporâneo ainda cumpre o importante papel de destacar as articulações de sentidos e inserir a interpretação em um projeto mais amplo e contextualizado, visando uma dada agenda contextual.

Dessa forma, a dramaturgia, em sua concepção contemporânea, consiste em instalar os elementos textuais e cênicos, investigar e destacar os significados variados do texto, direcionar uma interpretação em particular para 
a performance e, por fim, orientar o espetáculo no sentido escolhido (Pavis, 1998). Em resumo, dramaturgia hoje engloba as escolhas em termos estéticos, ideológicos e de significação que são feitas no processo de elaboração de um espetáculo, passando pelo estudo do texto e chegando à realização cênica. Ela será determinada conforme seu objetivo com o público (instruir ou meramente entreter, reproduzir ou fazer uma denúncia, etc).

Enquanto a dramaturgia implica a pessoa do dramaturgista como mediador literário e teatral no centro do processo de elaboração do espetáculo, a criação coletiva, especificamente, irá nitidamente descentralizar e desierarquizar o processo. O espetáculo resultado de uma criação coletiva não é assinado por uma única pessoa, e sim elaborado em grupo. Essa noção de coletividade na criação teatral foi impulsionada pelo trabalho de Jerzy Grotowski e de Eugenio Barba, que buscavam uma forma grupal constituída com um referente ideológico comunitário (JANIASKI, 2008). De fato, Pavis lembra que, para Brecht, tal trabalho coletivo pode ser definido como a "socialização do saber," ou seja, o texto e a encenação não representam mais a palavra de um autor, e sim a "marca mais ou menos visível e assumida da palavra coletiva" (PAVIS, 1998).

A esse respeito, Pavis observa que o advento da criação coletiva emergiu em um contexto de redescoberta do aspecto coletivo e ritual do fazer teatral, nos anos 1960 e 1970, bem como da vontade de explorar gestualidade, improvisação e comunicação não-verbal (PAVIS, 1998). Ainda, a criação coletiva reage contra a divisão e especialização do trabalho teatral, prezando pela colaboração entre pessoas que possuem semelhantes engajamentos artísticos, estéticos, ideológicos e políticos. Com efeito, a criação coletiva fundamenta-se na "identidade de propósito" em um dado núcleo de artistas (MAGALDI, 1985). Como um grupo assim coeso tem, naturalmente, dificuldade de encontrar pronto um texto que satisfaça seus anseios e agenda (MAGALDI, 1985), ele parte para um projeto elaborado por dezenas de mãos e mentes mentes que pensam de forma parecida.

$\mathrm{Na}$ criação coletiva, os atores reivindicam mais do que o papel de intérprete, buscando também o papel de artista criador, que muitas vezes escreve e dirige o espetáculo, englobando, por conseguinte, as tarefas de 
dramaturgista e encenador (MAGALDI, 1985). Além disso, grupos que desenvolvem esse tipo de criação normalmente realizam um projeto de longo prazo, com atividade continuada para o desenvolvimento de práticas pedagógicas na formação do ator (CARREIRA \& OLIVEIRA, 2003). Eles buscam também estabilidade de elenco (compreensível, uma vez que os integrantes do grupo se "encontram" por semelhanças ideológicas e estéticas), discutem o fazer teatral enquanto meio para realização de uma ação transformadora do sujeito humano (JANIASKI, 2008), e zelam pela liberdade de criação, de experimentação, e de especulação cênica criativa (ABREU, 2008), além da pesquisa artística coerente e rigorosa (PICON-VALLIN, 2008).

O processo de criação coletiva inicia com o interesse ou inquietação em torno de um tema julgado prioritário para os artistas em um dado contexto. A partir de tal interesse ou inquietação, o grupo faz improvisações para explorar seus posicionamentos e ideias (PAVIS, 1998), com cada participante propondo modificações em um processo de tentativas e erros. Assim, a criação coletiva desenvolve-se sem o apoio de um texto prévio, sendo o texto coletivo escrito, muitas vezes, paralelamente à criação da encenação por meio das improvisações. É justamente nesse processo de improvisações e experimentações que todos artistas do grupo acabam, de certa forma, tornando-se autores do projeto a ser encenado.

No projeto coletivo, evidentemente, existem diversas dificuldades não encontradas na autoria individual de uma peça. A criação coletiva não é simples de ser realizada, sendo um dos motivos complicadores os problemas interpessoais inevitáveis em dinâmicas de grupo (MAGALDI, 1985). Outra questão diz respeito à possível fragilidade de um texto concebido por muitos, que pode facilmente cair em fragmentação, esquematismo e desconexão entre elementos (MAGALDI, 1985). De fato, muitas vezes se faz necessária, em determinado momento, a coordenação dos elementos da encenação, através de uma liderança artística forte (ABREU, 2008), e o grupo pode ter dificuldade em reconhecer esse momento ou em aceitar essa coordenação e nova dinâmica. De acordo com Magaldi (1985), o ideal seria a presença de um dramaturgista enquanto conselheiro literário e teatral, que assegurasse o teor literário da experiência, e um encenador que, juntamente com o dramaturgista, 
ordenasse as sugestões coletivas. Assim, se preservaria os princípios da estética colaborativa, e o grupo seria estimulado a unificar suas ideias, estilistica e narrativamente. De fato, em muitos projetos de criação coletiva as dinâmicas de preparação do espetáculo fazem com que todos colaborem na criação do mesmo, porém as funções em termos de autoria textual podem ser mais ou menos delimitadas e particulares.

Como dito anteriormente, o projeto coletivo é normalmente motivado por uma necessidade de elaborar conjuntamente um espetáculo que atenda aos anseios de um dado engajamento ideológico e contextual dos integrantes do grupo. Veremos, na sequência, como a questão da apropriação tem uma motivação de ordem semelhante.

\section{O PROBLEMA DA APROPRIAÇÃO}

A apropriação de um texto base para o teatro difere substancialmente do processo chamado de adaptação. Enquanto que a adaptação toma o texto base como um roteiro de encenação, a apropriação desterritorializa e recontextualiza esse texto, para uso e benefício próprio (RESENDE, 1999). Nas palavras enfáticas de Lawrence Boswell (Apud O'SHEA, 2002), o texto original é espancado, retorcido e revirado, de modo a se tornar aquilo que o grupo quer expressar, conforme seu contexto e objetivos específicos. Assim, a apropriação "reedita [o texto] sob a luz de um novo prefácio" (CAVALCANTE, 2006), isto é, dentro de um novo contexto de objetivos e significação.

A apropriação é, antes de tudo, uma transformação radical do texto original e de suas mensagens estéticas e ideológicas. Como bem coloca Pavis (1992), um texto não fala por si, é preciso fazê-lo falar, e o diretor possui os meios para isso. Justamente a partir dessa prerrogativa é que o diretor encontra espaço para a apropriação, transformando e ressignificando o texto base a partir de dados contextos e propósitos da encenação, fazendo o texto falar o que é de interesse que seja dito. Afinal, como Pavis (1992) explica, é impossível "neutralizar" o palco para que o texto seja ouvido sem mediação ou distorção (tanto em processos de adaptação quanto de apropriação). A tentativa de não interferência é, em si, um passo ingênuo ou desonesto 
(PAVIS, 1992). A partir disso, a apropriação questiona o autor do texto base como detentor dos significados teatrais, e faz isso ao constituir ela mesma em um processo criativo e autoral (PAVIS, 2003). Com efeito, para Pavis, a apropriação equivale à escritura e encenação de um novo trabalho, igualmente original em relação ao trabalho que the serviu de ponto de partida. Desse modo, a apropriação resulta de/em interpretação, intervenção e desestabilização radical do texto original. Ela implica, também, em recriação e produção de novos sentidos (PAVIS, 2003), estimulando o "pensamento independente" daqueles que apropriam, por meio de uma atividade críticocriativa-interpretativa (CAVALCANTE, 2006).

Uma vez que a apropriação denuncia a necessidade de atualização e ressignificação do texto base, e "retorce" esse texto para novos fins e sentidos, a apropriação é uma reinvenção dentro dos interesses do novo contexto de recepção. Deste modo, como explica Margarida Gandara Rauen, a apropriação evita a fixação e transmissão de mentalidades inerentes à outras épocas (RAUEN, 2005). O texto é apropriado para que produza sentidos que tenham significado em sua situação de recepção, e para que essa apropriação possa, então, inspirar uma ação transformadora de tal situação. Dessa forma, nas palavras de Brecht lembradas por Rauen, o por que da apropriação reside na necessidade de um teatro que não proporcione apenas sensações, ideias e impulsos permitidos em um dado contexto, mas que também empregue e suscite pensamentos e sentimentos que ajudem a transformar tal contexto (RAUEN, 2005).

Assim, o problema central da apropriação no teatro contemporâneo está em estabelecer um diálogo frutífero entre a cultura e obra fonte e a cultura e obra alvo (PAVIS, 2003) Esse diálogo deverá ser pautado largamente pelos interesses locais e históricos (ideológicos, sociais, políticos...) que estão em foco no dado contexto de recepção da apropriação. Além disso, a apropriação, com suas intervenções e recriações textuais e teatrais, pode mudar tanto a forma como vemos o original (que se torna um lugar de contestação ao invés de detentor de significados essenciais e imutáveis), quanto a forma como vemos nós mesmos (O'SHEA, GUIMARÃES \& BAUMGÄRTEL, 2005) . Isso se deve ao fato que a apropriação pode ser lida como uma necessidade forte de 
auto-afirmação e de construção de identidade, em uma direção oposta a normas e valores do passado recebido (O'SHEA, GUIMARÃES \& BAUMGÄRTEL, 2005).

No entanto, nem sempre é fácil proceder com o projeto de uma apropriação. A esse respeito, Rauen (2005) sugere superar a possível barreira frente à uma suposta "violação" de um texto canônico, primeiramente, lembrando que mesmo um texto clássico possui múltiplas versões, resultado de um longo processo de transmissão (que inclui o trabalho do autor, do tradutor, do editor, do diretor, do ator...). Ainda conforme Rauen, a apropriação pode ser desenvolvida por meio da transposição do texto e da trama base para outra época e ambiente social e histórico, realizando-se as devidas atualizações necessárias (de linguagem ou de referências geográficas, por exemplo).

Outros procedimentos eficazes na apropriação, conforme Rauen (2005), incluem: questionar a mentalidade e visão de mundo de uma peça base em diálogo com uma mentalidade mais atual; modificar o gênero ou concepção geral da forma da peça, e fazer experimentos com o novo gênero ou concepção; e retomar um conflito da peça discutindo possíveis ampliações e soluções para o mesmo. Da mesma forma, é também possível escolher uma cena, personagem ou aspecto da peça base e colocá-lo em outra época, ideologia ou ambiente. Todos esses procedimentos abrem a dimensão ideológica do texto original para uma apropriação a partir de múltiplos novos olhares na cultura alvo (RAUEN, 2005).

Ao final do trabalho de apropriação, há que se verificar seu efeito ou potencial para transformação e para impacto de significados em seu contexto de recepção. Para tanto, é preciso observar como os signos são reagrupados, quais são os acréscimos, supressões e invenções em relação ao texto base, e que efeito estes possuem no novo texto e nos novos sentidos construídos na apropriação (CAVALCANTE, 2006). Deve-se, portanto, avaliar o quanto a apropriação é eficaz em fazer uso próprio do material apropriado, à luz de seus objetivos e interesses específicos e contextualizados. Em outras palavras, como a apropriação busca novas significações vis-à-vis seu contexto de recepção próprio e a agenda daqueles que apropriam, sua apreciação se dá 
precisamente em relação a sua capacidade de comunicar e significar para o seu público, em sua época, e com suas motivações e objetivos específicos.

\section{CONSIDERAÇÕES FINAIS}

Esse artigo discutiu a questão da criação coletiva de peças e espetáculos, e também o problema da apropriação de textos originais para o palco, fazendo referência a teorias e teóricos contemporâneos. É necessário, nesse momento, reafirmar a relação entre as duas questões em debate, pois um dado ponto principal emergiu em ambas discussões e deve ser agora frisado, especialmente em função de suas implicações para a cena e a atividade teatral do tempo presente.

A principal relação entre a questão da criação coletiva e o problema da apropriação, a meu ver, diz respeito a ambos processos serem realizados à luz de uma dada agenda e engajamento político, estético, artístico, social e ideológico. Espera-se que tenha ficado claro, ao longo da discussão conduzida, como o processo de criação coletiva ocorre em função da necessidade de um dado grupo produzir um texto que comunique seus anseios e engajamentos específicos, da mesma forma que o processo de apropriação é também motivado pela busca de novas significações, particularmente significações que façam sentido no contexto de recepção da apropriação, e que sejam coerentes com os objetivos e interesses por trás da mesma.

Portanto, na atividade teatral contemporânea, tanto os trabalhos de criação coletiva quanto os de apropriação buscam cumprir uma certa agenda e comunicar os sentidos não de um texto clássico e passado, mas sim de um texto escrito a diversas mãos ou reescrito sob a forma de um "espancamento" do texto original, para utilizar o termo de Lawrence Boswell novamente. Assim, a relação entre criação coletiva e o problema da apropriação encontra-se na busca por um teatro com poder de transformação, em uma perspectiva condizente com a de Richard Schechner, apresentada na introdução do estudo. Em outras palavras, o fazer teatral contemporâneo, por meio das atividades de criação coletiva e de apropriação, é capaz de proporcionar reflexões críticas para eventuais mudanças no mundo real, através da 
significação e comunicação, pela arte, de uma certa agenda estética e ideológica. Mais do que aplausos, a criação coletiva e a apropriação almejam impacto, reflexões críticas, e ações transformadoras.

\section{REFERÊNCIAS BIBLIOGRÁFICAS}

ABREU, Kil. Experimentação e realidade: Grupos e modos de criação teatral no Brasil. In: Próximo ato: Questões da teatralidade contemporânea. Orgs. Fátima Saadi \& Silvana Garcia. São Paulo: Itaú Cultural, 2008. p. 90-95.

CARREIRA, André \& Valéria Maria de Oliveira. Teatro de grupo: Modelo de organização e geração de poéticas.In: O Teatro Transcende $n^{\circ} 12$. Blumenau: FURB, 2003. p. 95-98.

CAVALCANTE, Alex Beigui de Paiva. Dramaturgia por outras vias: $A$ apropriação como matriz estética do teatro contemporâneo - do texto literário à encenação. Tese de doutorado. USP, 2006. Disponível em http://www.teses.usp.br/teses/disponiveis/8/8149/tde-23082007-131724/ptbr.php (acesso em outubro de 2010).

JANIASKI, Flávia. O produtor e o produto no teatro de grupo. In: Urdimento: Revista de estudos em artes cênicas vol. 1 n¹1. Florianópolis: UDESC, 2008. p. 67-77.

LUCKHURST, Mary. Revolutionising theatre: Brecht's reinvention of the dramaturg. In: The Cambridge Companion to Brecht. Eds. Peter Thomson \& Glendyr Sacks. 2ª ed. Cambridge: Cambridge University Press, 2006. p. 193208.

Magaldi, Sábato. Iniciação ao teatro. São Paulo: Ática, 1985.

O'SHEA, José Roberto. Performance e inserção cultural: Antony and Cleopatra e Cymbeline, King of Britain em português. Cimbeline, rei da Britânia. Trad. José Roberto O'Shea. São Paulo: Iluminuras, 2002. p. 29-43. 
O'SHEA, José Roberto, Daniela Lapoli Guimarães, \& Stephan Arnolf Baumgärtel. Shakespeare's drama: Appropriation on page, stage, and celluloid. In: Ilha do Desterro n 49. Florianópolis: UFSC, 2005. p. 11-23.

PAVIS, Patrice. Analyzing performance: Theatre, dance, and film. Trad. David Williams. Ann Arbor: University of Michigan Press, 2003.

. Dictionary of the theatre: Terms, concepts, and analysis. Trad. Christine Shantz. Toronto: University of Toronto Press, 1998.

. Theatre at the Crossroads of Culture. Trans. Loren Kruger. London: Routledge, 1992.

PICON-VALLIN, Béatrice. A propósito do teatro de grupo. Ensaio sobre os diferentes sentidos do conceito. In: Próximo ato: Questões da teatralidade contemporânea. Orgs. Fátima Saadi \& Silvana Garcia. São Paulo: Itaú Cultural, 2008. p. 82-89.

RAUEN, Margarida Gandara. Apropriação criativa dos cânones em novos roteiros e linguagens. In: Ilha do Desterro n 49. Florianópolis: UFSC, 2005. p. 369-396.

RESENDE, Aimara da Cunha. God bless thee! Thou art translated! On two Brazilian Tempests. Ilha do Desterro n³6. Florianópolis: UFSC, 1999. p. 237264.

SCHECHNER, Richard. Performance Theory. London: Routledge, 1988. 